\title{
Malnutrition and Associated Disorders Among Pregnant Women in Keranigonj, Bangladesh
}

\author{
Sayeeda Zakia Khanam ${ }^{1}$ and Hamida Khanum ${ }^{2,3 *}$ \\ ${ }^{1}$ Consultant, Gynae@ Obs, Shaphena General Hospital Ltd. Dit Rd, Dhaka, Bangldesh \\ ${ }^{2}$ American International University, Bangladesh
}

${ }^{3}$ Professor, Department of Zoology, University of Dhaka, Bangladesh

*Corresponding author: Hamida Khanum, Professor, Department of Zoology, University of Dhaka, Bangladesh

\section{ARTICLE INFO}

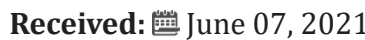

Published: 蔧 June 18, 2021

Citation: Sayeeda Zakia Khanam, Hamida Khanum. Malnutrition and Associated Disorders Among Pregnant Women in Keranigonj, Bangladesh. Biomed J Sci \& Tech Res 36(4)-2021. BJSTR. MS.ID.005881.

\section{ABSTRACT}

The low dietary intake of iron, folic acid and food stuffs that promote iron absorption, coupled with poor bioavailability of iron are the major factor responsible for very high prevalence of malnutrition in this country. To assess the status of Malnutrition and associated disorders among pregnant women in Keranigonj, the present study was conducted in the Department of Obstetrics and Gynecology of a tertiary care hospital in Keranigonj, Dhaka, Bangladesh, from September to December 2018. A total number of pregnant women with malnutrition who came to check-up in this hospital were selected as study group. This was descriptive type of Cross-sectional study. According to the present study, among the individual's chance of developing malnutrition increases with the age. It has been proved statistically significant (p-value: 0.05 ) in the current study. Teenage pregnancy is associated with maternal anemia, preterm labor, urinary tract infection. We have also found that, in our study population among 51.85\% teenage mothers with various complications, $22.22 \%$ had anemia. Our study has shown that among $75 \%$ older women with complications, $38.77 \%$ suffered from malnutrition. It can be concluded that among the respondent $44 \%$ presented with malnutrition and the associated risk factors included socio-economic factors, behavioral factors, clinical factors and reproductive factors. Pregnancy related complications are still major problems in Bangladesh even though Bangladesh is well on its way towards achieving the Sustainable Development Goal 5 (Improving Maternal Health).

\section{Introduction}

Maternal iron deficiency and anemia render the offspring vulnerable for developing deficiency and malnutrition right from infancy. This could help explain many of the inter-related variables which come into play in explaining the prevailing situation in the Keranigonj of Bangladesh [1]. Malnutrition in women, including pregnant women, is not conspicuous and remains, to a large extent, uncounted and unreported; thus, insufficient attention has been given to the extent, causes, and consequences of malnutrition in women [2]. As a result, inadequate resources and efforts have been allocated to improve women's nutrition compared with other nutritional and public health actions $[3,4]$. It was suggested that highly publicized initiatives such as "child survival" and "safe motherhood" have not had the expected effect because too little attention has been given to the nutritional status of women, including mothers $[1,5,6]$.

Some 200 million women become pregnant each year, most of them in developing countries [7]. Many of these women suffer from both ongoing nutritional deficiencies and the long-term cumulative consequences of under nutrition during childhood. Pregnancy-related health and nutritional problems including the hygiene knowledge affect a woman's quality of life, that of her newborn infant well beyond delivery, and that of her family and community. McGuire and Poplin's (1989) [8] reviewed of studies on the nutritional status of pregnant and lactating women showed that 
women in developing countries like Bangladesh consumed only about two-thirds of the recommended daily intake of energy and that their average weight for height was, in most cases, well below the 50th percentile for small-framed women in developed countries [9]. The nutritional requirements of pregnant and lactating women were significantly greater. The study by Black et al (1994) [10], showed that micronutrient deficiencies, particularly deficiencies of iron and vitamin B-12, were frequent in pregnant women in Bangladesh. Poor health, hygiene and nutrition are associated with repeated, closely spaced pregnancies that progressively reduce women's nutritional reserves to the point of nutritional depletion [11-13].

Studies have shown that iron deficiency is the main cause of malnutrition followed by folate deficiency. In Bangladesh, the prevalence of malnutrition is high because of low dietary intake, poor iron (less than $20 \mathrm{mg} /$ day) and folic acid intake (less than $70 \mathrm{mg} /$ day); poor bioavailability of iron (3-4\% only) in phytate and fibre rich Bangladeshi diet and Chronic blood loss due to infection such as malaria and hookworm infections. Malnutrition gets aggravated by increased requirements during adolescent and during pregnancy. Maternal iron deficiency and anemia render the offspring vulnerable for developing deficiency and malnutrition right from infancy. With the onset of menstruation and associated blood loss, there is a further rise in prevalence and severity of malnutrition in adolescent girls. One of the main contributors to this situation is the miserable condition of the women in rural area and urban slum area, eg. protein, while $20 \%$ of the population has even lower levels energy intake of less than 380 kilojoules [7] The purpose of this study was to find Malnutrition and associated disorders among pregnant women in Keranigonj which might provide a comprehensive picture about the said situation to the concern people and thus help to carry out further study to increase the knowledge about malnutrition and associated disorders among pregnant women $[14,15]$.

Justification of the study: Although there has been a tremendous achievement in primary health care (PHC) in Bangladesh, there has been marked failure in some activities, the most gloving being almost no achievement in improvement of nutritional status of the women of reproductive age especially in rural areas, postpartum care, etc. Overall, the findings of the present study will form part of a baseline for the malnutrition assessment for pregnant women in Dhaka. It is also found that although Bangladesh made an satisfactory for pregnant gain in maternal health but still postpartum care practice is very low and it differs from region to region and different socio-economic status. Only one fifth of the mothers sought post-partum care against 50 percent ante natal care. It is also evident that post-partum contraceptive method acceptance is very low and most of the mothers do not know about post-partum methods [16].

\section{Materials and Methods}

This was a cross sectional, descriptive type and quantitative type of study. For the purpose of the study, the target population were pregnant mothers in Keranigonj, was carried out from July 2019 to December, 2019. Semi-structural questionnaire was used for callection of necessary information. A check list or medical record review were done for the assessment of the health of the Pregnant Mothers Information regarding socio demographic, behavioral, clinical and reproductive characteristics were collected using a structured questionnaire, data were analyzed by SPSS version 16.0 program and by descriptive statistics and inferential statistics. Logistic regression were done for multi variants analysis to control the potential confounding factors. Ethical Considerations: The project proposal were approved by a competent ethical committee of AIUB. All ethical principles and norms were followed before starting data collection. There limitation in this study as it was done in only three Hospital around Keranigonj.

\section{Results}

The present study was conducted on Malnutrition and associated disorders among pregnant women in Keranigonj, Dhaka during the study period July 2019 to November 2019. The aim of the study was to assess the status of Malnutrition and associated disorders among pregnant women in Keranigonj. It was found that more than half $(51.85 \%)$ of the respondents with age less than 20 years were suffering from malnutrition. Age group with 20 to 29 years $(74.22 \%)$ was suffering from malnutrition and pregnant women with age 30 years and above $75 \%$ patients were facing with malnutrition (Figure 1).

\section{Demographic Information of the Respondents:}

Age of the Respondents: The age range of these women was divided into three categories shown in Figure 1, where 9\% respondents were below 20 years, $75 \%$ were 20 to 29 years and about $16 \%$ were in 30 years and above (Figure 1).

Educational Status of the Respondents: Levels of education of the respondents were classified as Illiterate, Primary, SSC, HSC, Under Graduate, Graduate and Post Graduate are recorded data shows that $14.66 \%$ were illiterate or they had no schooling, $16.33 \%$ passed primary, $24 \%$ passed SSC, $25 \%$ passed HSC, $14.33 \%$ was undergraduate, $4.66 \%$ graduate and $1 \%$ was post graduate (Figure 2). Levels of education of the respondents were classified as Illiterate, Primary, SSC, HSC, Under Graduate, Graduate and Post Graduate are recorded data shows that $14.66 \%$ were illiterate or they had no schooling, $16.33 \%$ passed primary, $24 \%$ passed SSC, $25 \%$ passed HSC, $14.33 \%$ was undergraduate, $4.66 \%$ graduate and $1 \%$ was post graduate (Figure 2). 


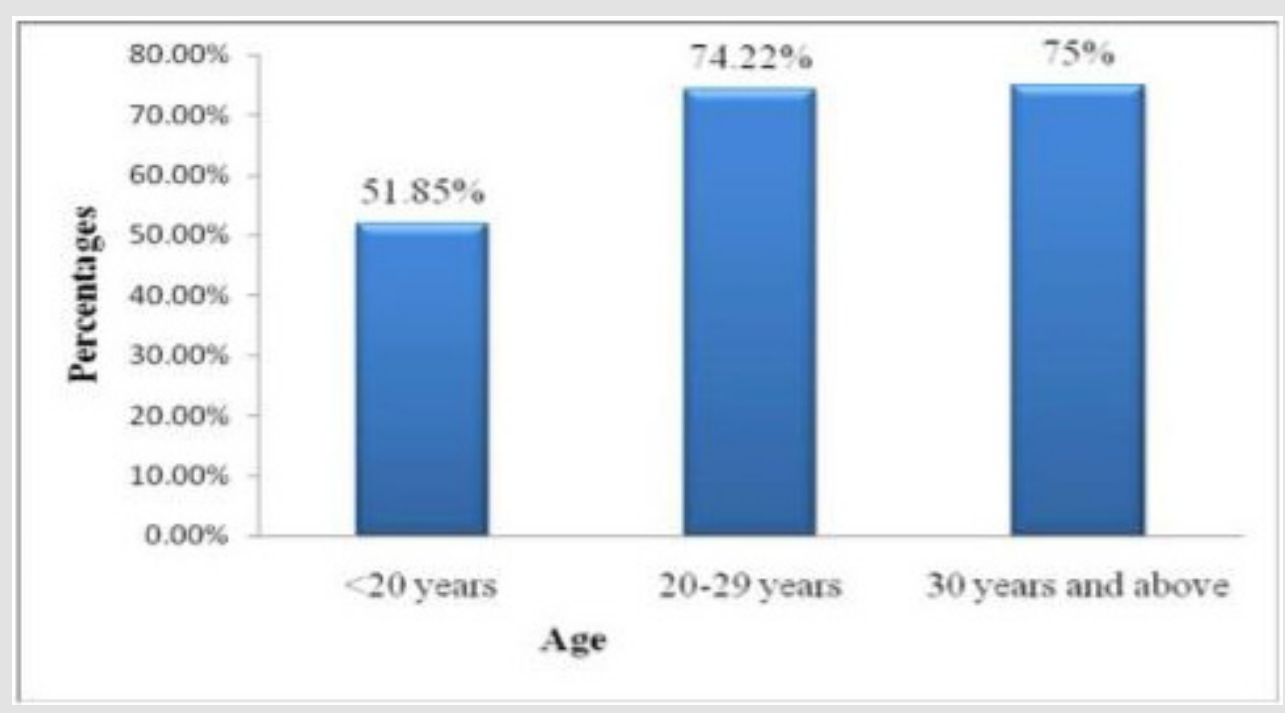

Figure 1: Patients with different complications within different age groups in the sample population.

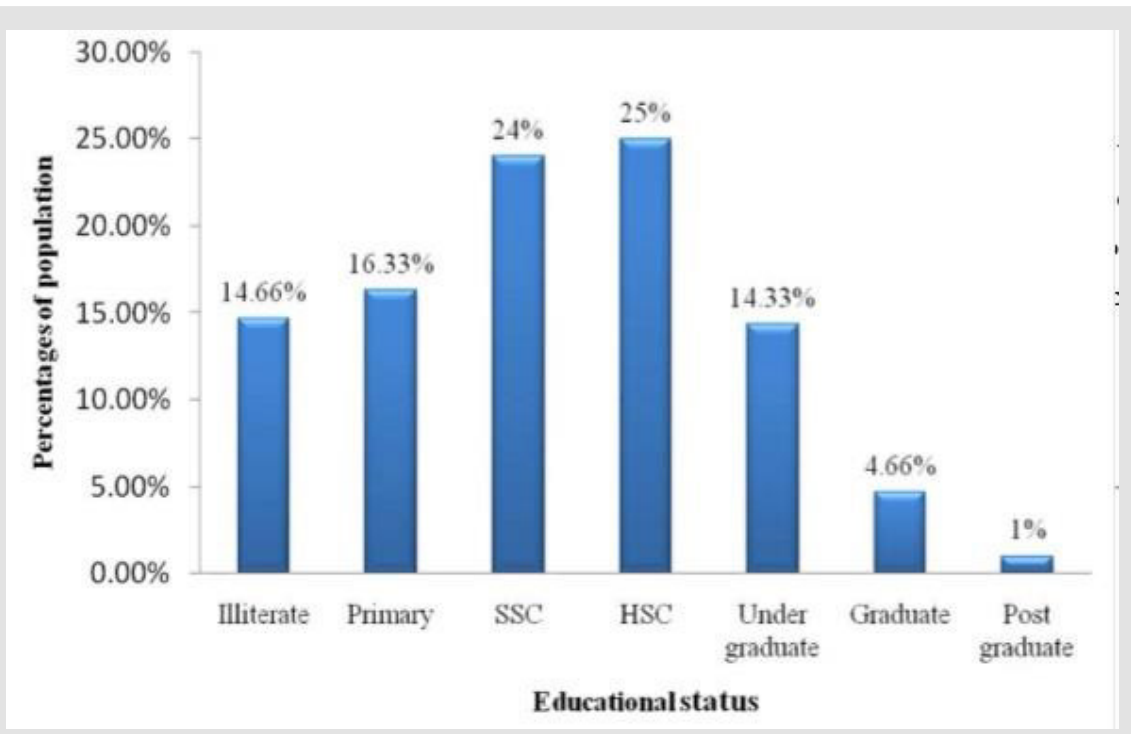

Figure 2: Educational status of sample population.

In the present study, there were different family income pattern for each respondent which is represented their different socio-economic condition, there were different family income pattern for each respondent which is represented their different socio-economic condition. About $24 \%$ respondents family income were below five thousand, $37 \%$ care-givers family income were five thousand to nine thousand nine hundred ninety nine as well as 39\% respondents family income were more than ten thousand taka per month. In the present study, there were different family expenditure pattern for each respondent which is represented their different socio-economic condition. According to this table shows that $18 \%$ respondents family expenditure were below five thousand due to less income source and led a worst life, 37\% care- givers family expenditure were five thousand to nine thousand nine hundred ninety-nine as well as $45 \%$ respondents family expenditure were more than ten thousand taka per month due to having more earning member at different age in the family which is related to the malnutrition of the pregnant women.

Obstetric history of respondents: Total obstetric history of the sample population with the abnormality. Preterm birth, gestational diabetes, and, they had during and before pregnancy. preeclampsia were more common among older mother. In the recorded data, maximum women $(39.66 \%)$ had in their second gravida. The proportion of others were first grevida (35\%), gravida $3(16 \%)$, gravida 4 (6\%), graviada 5 (2.66\%), gravida $6(0.33 \%)$ (Figure 3$)$. 


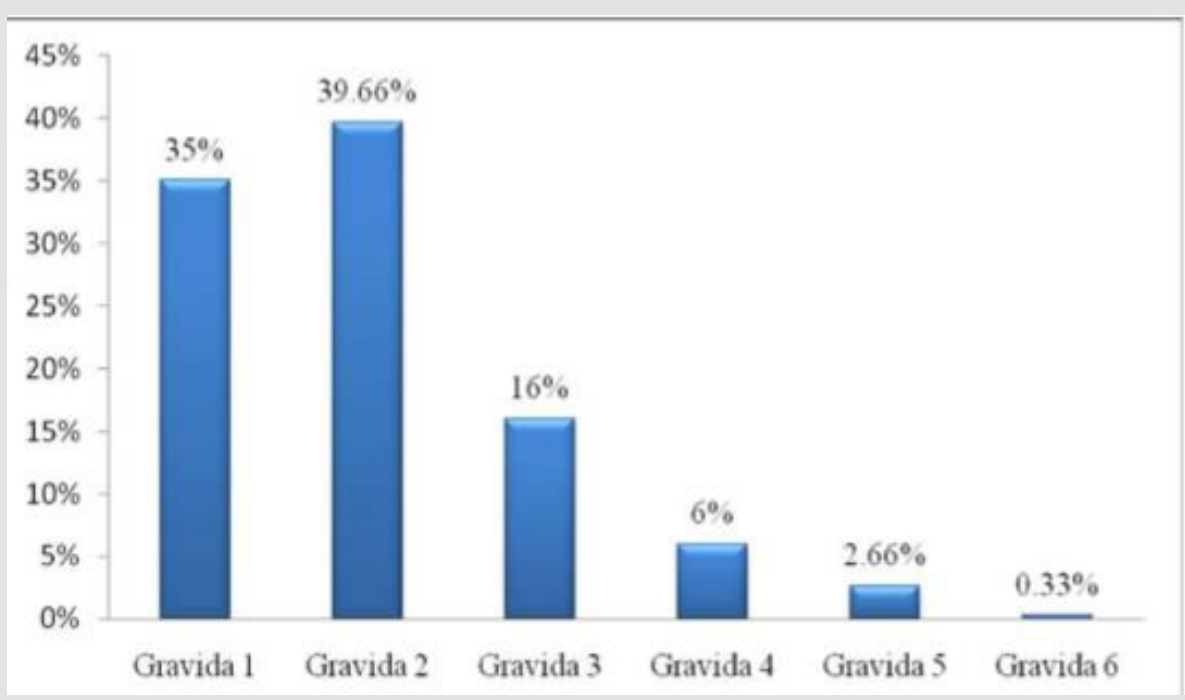

Figure 3: Total number of pregnancies in sample women.

Socio-demographic and economic Factors: Attempt has been made to show the relation between socio economic, behavioral, clinical and reproductive factors of malnutrition pregnant patients. Maternal Age, Occupation, Residence, Family care, Exercise habit, Pre-existing Diabetes, anemia, Number of children and $\mathrm{H} / \mathrm{O}$ Abortion or Miscarriage seem to be a risk factor for developing malnutrition during 3rd trimester of pregnancy as $p$ values are less than 0.05 (Table 1). However, Level of Education level has no significant effect on developing different types of malnutrition factors during 3rd trimester as p value is more than 0.05 , which is not statistically significant. It is very important to the age of the

Table 1: Relationship with socio-demographic variables. respondent mothers during the first pregnancy (In years) which is showed on the graph where $56 \%$ respondent mothers faced the first pregnancy at the age of 16-20 years old, $41 \%$ respondent mothers faced their first pregnancy at less than 15 years old and $3 \%$ respondent mothers faced the first pregnancy at more than 21 years old in the present study (Figure 3 ). The most commonly mentioned issue was concern about knowledge of the malnutrition among the child where $67 \%$ pregnant women knew about the malnutrition and 33\% pregnant women did not know about the malnutrition which is showed on the figure of the present study (Figure 3).

\begin{tabular}{|c|c|c|c|c|c|}
\hline \multirow[t]{2}{*}{ Variables } & \multirow[t]{2}{*}{ Categories } & \multicolumn{2}{|c|}{ Malnutrition } & \multirow[t]{2}{*}{$x^{2}$ value } & \multirow[t]{2}{*}{$p$ value } \\
\hline & & Y & $\mathrm{N}$ & & \\
\hline \multirow{2}{*}{ Maternal Age } & $<=30$ & 43 & 112 & \multirow{2}{*}{130.36} & \multirow{2}{*}{$<0.001$} \\
\hline & $>30$ & 105 & 0 & & \\
\hline \multirow{3}{*}{ Level of Education } & Primary & 49 & 42 & \multirow{3}{*}{3.98} & \multirow{3}{*}{0.14} \\
\hline & Secondary & 69 & 39 & & \\
\hline & Higher Secondary \& Above & 30 & 31 & & \\
\hline \multirow{2}{*}{ Occupation } & Employed & 90 & 39 & \multirow{2}{*}{16.2} & \multirow{2}{*}{$<0.001$} \\
\hline & Unemployed & 58 & 73 & & \\
\hline \multirow{2}{*}{ Residence } & Rural & 27 & 3 & \multirow{2}{*}{13.65} & \multirow{2}{*}{0.0002} \\
\hline & Urban & 121 & 109 & & \\
\hline \multirow{2}{*}{ Malnutrition } & No & 97 & 107 & \multirow{2}{*}{32.19} & \multirow{2}{*}{0.001} \\
\hline & Yes & 51 & 5 & & \\
\hline \multirow{2}{*}{ Family H/O CVD } & $\mathrm{N}$ & 59 & 67 & \multirow{2}{*}{9.38} & \multirow{2}{*}{0.002} \\
\hline & $\mathrm{Y}$ & 89 & 45 & & \\
\hline \multirow{2}{*}{ Pre-existing Diabetes } & $\mathrm{N}$ & 64 & 70 & \multirow{2}{*}{8.71} & \multirow{2}{*}{0.003} \\
\hline & Y & 84 & 42 & & \\
\hline \multirow{2}{*}{ BMI } & $\mathrm{N}$ & 59 & 67 & \multirow{2}{*}{9.38} & \multirow{2}{*}{0.002} \\
\hline & $\mathrm{Y}$ & 89 & 45 & & \\
\hline
\end{tabular}




\begin{tabular}{|c|c|c|c|c|c|}
\hline \multirow{2}{*}{ BMI } & $\mathrm{N}$ & 64 & 70 & \multirow{2}{*}{8.71} & \multirow{2}{*}{0.003} \\
\hline & $\mathrm{Y}$ & 84 & 42 & & \\
\hline \multirow{2}{*}{ Anemia } & No & 43 & 112 & \multirow{2}{*}{16.88} & \multirow{2}{*}{$<0.001$} \\
\hline & Yes & 105 & 0 & & \\
\hline \multirow{3}{*}{ Number of Children } & 1 & 58 & 31 & \multirow{3}{*}{23.27} & \multirow{3}{*}{$<0.001$} \\
\hline & $2+$ & 26 & 03 & & \\
\hline & None & 64 & 78 & & \\
\hline
\end{tabular}

It is very important to the age of the respondent mothers during the first pregnancy (In years) which is showed on the graph where 56\% respondent mothers faced the first pregnancy at the age of 16-20 years old, 41\% respondent mothers faced their first pregnancy at less than 15 years old and 3\% respondent mothers faced the first pregnancy at more than 21 years old in the present study (Figure 4). The most commonly-mentioned issue was concern about knowledge of the malnutrition among the child where $67 \%$ pregnant women knew about the malnutrition and 33\% pregnant women did not know about the malnutrition which is showed on the figure of the present study (Figure). It is very important to the age of the respondent mothers during the first pregnancy (In years) which is showed on the graph where 56\% respondent mothers faced the first pregnancy at the age of 16-20 years old, $41 \%$ respondent mothers faced their first pregnancy at less than 15 years old and 3\% respondent mothers faced the first pregnancy at more than 21 years old in the present study (Figure 4). The most commonly-mentioned issue was concern about knowledge of the malnutrition among the child where 67\% pregnant women knew about the malnutrition and 33\% pregnant women did not know about the malnutrition which is showed on the figure of the present study.

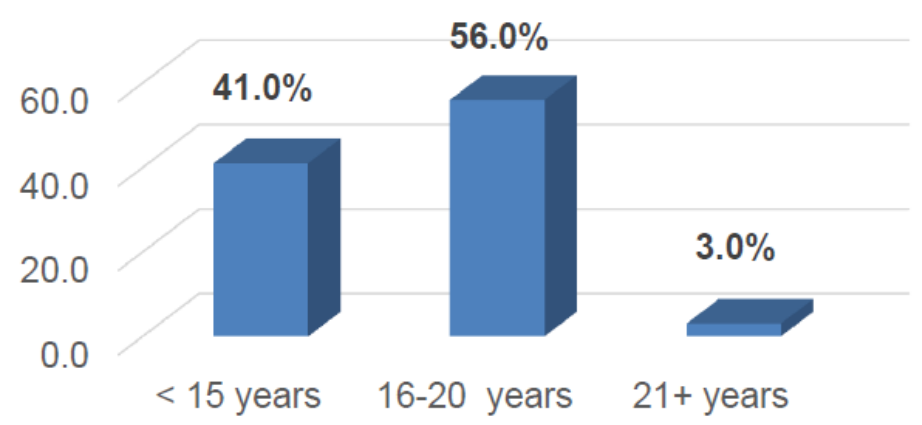

Figure 4: The age of the respondent mothers during the first pregnancy (In years).

The Table no 2 showed that $64.12 \%$ respondents had Normal Blood Pressure (Below 120/80 mmHg); 30.39\% respondents had Pregnancy induced hypertension and 5.49\% respondents had Hypertensive crisis (emergency are needed) to find in this study. In case of gestational hypertension $51.11 \%$ patient had a previous history of pregnancy hypertension, $24.18 \%$ had chronic hypertension. In case of gestational hypertension $51.11 \%$ patienthad a previous history of pregnancy hypertension, $24.18 \%$ had chronic hypertension. We found significant association between history

Table 2: Blood pressure ranges of the respondents. of hypertension during previous pregnancy and hypertension in current pregnancy. This study revealed significant association of hypertension in pregnancy with history of paternal hypertension, but no association with history of maternal hypertension. The study revealed a greater risk of having hypertension during pregnancy for women with history of paternal hypertension and also reported no significant difference between history of maternal hypertension and hypertension in pregnancy Table 2 .

\begin{tabular}{|c|c|c|}
\hline Stages & Blood Pressure & Percentages of the Patient (\%) \\
\hline Normal Blood Pressure & Below 120/80 mmHg & 64.12 \\
\hline Pregnancy induced hypertension & $\begin{array}{c}(120-139) \mathrm{mmHg} \text { systolic pressure and (80-89) mmHg } \\
\text { diastolic pressure. }\end{array}$ & 30.39 \\
\hline Hypertensive crisis (emergency are needed) & $\begin{array}{c}\text { Systolic pressure is higher than } 180 \mathrm{mmHg} \text { and mm Hg diastolic } \\
\text { pressure is higher than } 110 \mathrm{mmHg}\end{array}$ & 5.49 \\
\hline
\end{tabular}


A significant association between history of hypertension during previous pregnancy and hypertension in current pregnancy was evident. The present study revealed significant association of hypertension in pregnancy with history of paternal hypertension, but no association with history of maternal hypertension, a greater risk of having hypertension during pregnancy for women with history of paternal hypertension and also reported no significant difference between history of maternal hypertension and hypertension in pregnancy. Some parameters are extremely associated with pregnancy induced hypertension and the possibility of being presence of these parameters in our sample population with PIH. Percentages of the patient's with these parameters are given in Table 3 (Figure 5).

Table 3: Reason behind the malnutrition of the respondents.

\begin{tabular}{|c|c|}
\hline Reason behind the malnutrition among the pregnant women & Percentage (\%) \\
\hline Inappropriate care & 50 \\
\hline Inappropriate environment & 26.2 \\
\hline Inappropriate food & 33.3 \\
\hline Too many children & 68.4 \\
\hline Dirty kitchen & 26.5 \\
\hline Poor food quality & 35.6 \\
\hline Lack of knowledge & 20 \\
\hline Base, $\mathrm{n}$ & 260 \\
\hline
\end{tabular}

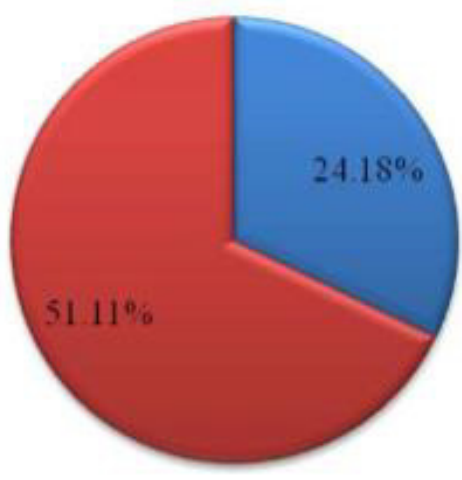

u Pregnancy induced hypertension chonichypertension

Figure 5: History of hypertension among the respondent.

Reason behind the malnutrition among the pregnant women: In the present study, there were reasons behind the malnutrition of each respondent which is represented their different socioeconomic condition. According to this table shows that $68.4 \%$ pregnant women suffered malnutrition due to have many children which following to $50.0 \%$ pregnant women suffered malnutrition due to in appropriate care of the family. The proportion of $35.6 \%$ pregnant women suffered malnutrition due to poor food quality, $33.3 \%$ pregnant women suffered malnutrition due to in appropriate food, and $26.5 \%$ pregnant women suffered malnutrition due to in appropriate environment and dirty kitchen of their living area.
Whereas, 20\% pregnant women suffered malnutrition due to lack of knowledge about it among them to find this study Table 5).

Weight gain during pregnancy has considered as continuous variables. It indicates that, women who gained weight more than $20 \mathrm{~kg}$ during their pregnancy are more prone to develop preeclampsia than the women who gained less than $20 \mathrm{~kg}$ of weight during 3rd trimester. Majority of the pregnant patients (70\%) had persistence headaches, (11\%) had blurred vision, $(67 \%)$ had abdominal pain, and (4\%) had sensitivity of light to find in this study (Table 4). 
Table 4: Adjusted analysis between variables and Malnutrition.

\begin{tabular}{|c|c|c|c|c|}
\hline Variables & Reference & Estimate & OR & p-value (5\%) \\
\hline Maternal Age & & 0.69 & 2 & $<0.001$ \\
\hline Level of Education (Secondary) & Primary & 0.13 & 1.4 & 0.9 \\
\hline $\begin{array}{l}\text { Level of Education (Higher Secondary \& } \\
\text { Above) }\end{array}$ & Primary & -0.21 & 0.88 & 0.86 \\
\hline Occupation (Unemployed) & Employed & 1.2 & 3.3 & 0.15 \\
\hline Residence (Urban) & Rural & -3.69 & 0.32 & 0.003 \\
\hline Anemia (Yes) & No & 2.21 & 9 & 0.03 \\
\hline Exercise Habit (Yes) & No & -1.44 & 0.84 & 0.06 \\
\hline Pre-existing Diabetes (Yes) & No & 0.63 & 1.88 & 0.48 \\
\hline BMI (Yes) & No & -0.42 & 0.36 & 0.61 \\
\hline H/O Abortion \& Miscarriage (Yes) & No & 0.72 & 2.06 & 0.41 \\
\hline Weight loss & & 0.26 & 1.29 & 0.006 \\
\hline
\end{tabular}

Presence of hypertension can be predicted by noticing some signs or symptoms. In our study we have found that $73.62 \%$ patient felt dizziness or excessive vomiting and nausea, $64 \%$ had abdominal pain and $60 \%$ had severe headache. Though these symptoms are almost similar to the normal pregnancy symptoms, they might be sometimes useful. The present study indicated that the prevalence of hypertension in pregnancy was significantly higher in pregnant women with gestational period $\leq 20$ weeks $(10.0 \%)$ than women with gestational period $>20$ weeks (5.3\%). However, in various hospital-based studies, frequency of malnutrition was found to be higher which manifests after 20 weeks of gestation. In present study, prevalence of hypertension in pregnancy was found significantly higher in women with history of hypertension in previous pregnancy $(40.5 \%)$ compared to those with no history of hypertension in previous pregnancy (5.5\%), 64.12\% respondents had Normal Blood Pressure (Below 120/80 mmHg); 30.39\% respondents had Pregnancy induced hypertension and 5.49\% respondents had Hypertensive crisis (emergency are needed) to find in this study (Table 5).

Table 5: Blood pressure range of the respondents.

\begin{tabular}{|c|c|c|}
\hline Stages & Blood Pressure & $\begin{array}{c}\text { Percentages of the Patient } \\
\text { (\%) }\end{array}$ \\
\hline Usual Blood Pressure & Below 120/80 mmHg & 64.12 \\
\hline Pregnancy induced hypertension & $(120-139) \mathrm{mmHg}$ systolic pressure and (80-89) mmHg diastolic pressure. & 30.39 \\
\hline $\begin{array}{c}\text { Hypertensive crisis (emergency are } \\
\text { needed) }\end{array}$ & $\begin{array}{c}\text { Systolic pressure is higher than 180 mmHg and mmHg diastolic pressure is } \\
\text { higher than 110 mmHg }\end{array}$ & 5.49 \\
\hline
\end{tabular}

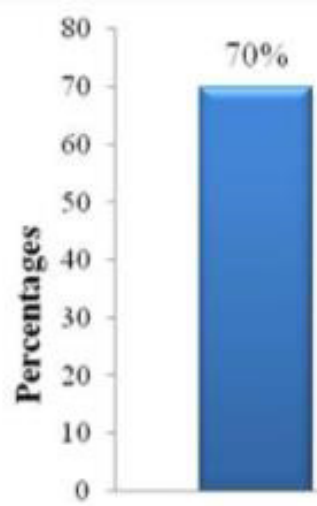

Persistent headaches
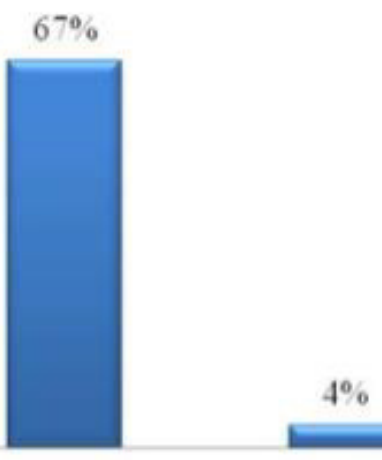

Blurred vision Abdominal pain Sensitivity to light

\section{Symptoms}

Figure 6: Patients experienced various symptoms. 
Blood pressure range of the pregnant women: In the present observation, $51.11 \%$ patient with a previous history of pregnancy induced hypertension, $24.18 \%$ with chronic hypertension and $48.35 \%$ with a family relative with hypertension. We have listed some other related factors which may arise with hypertension. We have found $2.19 \%$ patient with kidney diseases, $23.08 \%$ were facing with rapid or sudden weight gain, $19.78 \%$ have tested urine for presence of protein and $61.54 \%$ experienced of swelling of hands, feet and face (Figure 6).

\section{Discussion}

Complications of pregnancy and childbirth cause more deaths and disability than any other reproductive health problems. The situation is worse in developing countries like ours in Bangladesh due to inadequate access to modern health services and poor utilization and lack of awareness of the population about the complications and also for not likely to practicing some factors that is important to follow in pregnancy. The present study was designed to find out the risk factors of malnutrition among 3rd trimester pregnant women. Among the respondent 44\% presented with different types of malnutrition factors. A condition in pregnancy characterized by high blood pressure, sometimes with fluid retention and proteinuria. Age itself has been recognized as a risk factor for developing anemia, weight loss during 3rd trimester of pregnancy. According to the present study, individuals chance of developing malnutrition increases with the age. It has been proved statistically significant (p-value: 0.05 ) in the current study. Teenage pregnancy is associated with maternal anemia, preterm labour, urinary tract infection. It was also found that, in our study population among $51.85 \%$ teenage mothers with various complications, $22.22 \%$ had anemia. Preterm birth, gestational diabetes, and preeclampsia were more common among older mother (Jacobson, et al. 2004). The present study showed that among $75 \%$ older women with complications, $38.77 \%$ suffered from malnutrition.

It has been suggested that if someone is of an advanced maternal age she is more likely to develop malnutrition disorder than younger women. Of the women over the age of 35 studied in the sample, $9.4 \%$ had preeclampsia. Only $6.4 \%$ of younger women were afflicted. While there were other uncontrolled variables in this sample, such as maternal diabetes, smoking and other fertility treatments, the results are clear enough to determine that age does in fact effect of different types of malnutrition disease (Viteri 1994). From the study we found that the women with higher educational status like undergraduate, graduate or post graduate were more conscious about their pregnancy period, complications and also very much positive in taking care of those factors that could minimize the threat to their baby as well as to them. In a word they actually very much concerned about their new baby [18].
On the contrary, the sample populations who were not educated or possessed a poor educational background like with primary or SSC or HSC level, maximum respondents did not have pretty much knowledge about their pregnancy period, their new baby and all the stuff related to it. Even they did not know if they had any complication(s) or what the complication(s) was/were. If they gave stillbirth or if they had miscarriage, abortion they even did not know the reasons behind this. But it was a great shock that about $79.99 \%$ of the sample population either illiterate or had a poor educational background and only $20.01 \%$ had higher educational status. It is also seen that women with poor educational background possessed a lower economic status. Even they could not give birth to their baby in a hygienic environment [1,18-21].

According to the present, study Education level has an impact over developing anemia. Pregnant women with Primary level education are 1.4 times less likely to develop anemia than who are educated up to Secondary level and 22\% less likely to develop anemia than higher secondary and above level educated women. However, these are not statistically significant as $p$ $>0.05$. Occupation of pregnant mother plays an important role for developing malnutrition during 3rd trimester of pregnancy. It is seen that women who are not associated with any form of employment are developing 3 times more malnutrition than who are involved in any kind of employment, which is not statistically significant as p-value is more than 0.05 . It has been observed that Family H/O Preeclampsia plays an important role. In this study $\mathrm{p}$ value 0.03 proves that women whose any family member suffered from Preeclampsia are 9 times more likely to develop preeclampsia during their 3rd trimester of pregnancy than the women who has no family history. Exercise habit has significant impact over developing obesity. Women who walk at least 15 min per day are $16 \%$ less likely to develop obesity than who does not walk during 3rd trimester of pregnancy, which is statistically significant as $p$ value is 0.06 . According to this study, women whose any family member suffer from any form of CVD are 8 times more likely to develop preeclampsia than whose family member do not suffer from CVD. However, this is not statistically significant as $\mathrm{p}$ value is more than 0.05 (Royston and Armstrong 1989).

In the present observation, history of pre-existing diabetes has an important in developing different types of health problem. It is evident that who has previous history of above mentioned illness are 1.8 times more likely to develop different types of health problem than the women who do not have. This statistically is not significant as $\mathrm{p}<0.48$. Also, women who have previous $\mathrm{H} / \mathrm{O}$ abortion or miscarriage are 2 times more likely to develop preeclampsia than who has not such history. However, these are not statistically significant as $p$ value is more than 0.05 .

It is clearly evident that women whose weight were below 45 kg during pre-pregnancy are less likely to develop malnutrition 
during $3+$ trimester of pregnancy than the women whose weight were above $50 \mathrm{~kg}$ during pre-pregnancy. Weight gain is statistically significantly associated with developing preeclampsia during 3rd trimester of pregnancy as p-value is 0.006 . According to this study woman who gained weight more than $20 \mathrm{~kg}$ during pregnancy are more prone to develop preeclampsia than the women who gained less than 20kg during 3rd trimester (Lettenmeier et al.) [22].

In the present study, prevalence in the age group $\geq 25$ years was found to be significantly higher (9.9\%) as compared to age group $<25$ (5.9\%). In accordance with our study, it is identified that the risk of developing PIH tends to increase with maternal age. In comparison with women aged 20-25 years, the odds ratio (OR) was 3.5 in women aged 26-30 years and 4.2 in those aged $>30$ years. Higher incidence of PIH among literates, though the difference was not significant in our study. Higher incidence observed in literate women correlates with a report which states that those with college education had a $19 \%$ great chance of having malnutrition. Our study revealed no significant association between occupation and hypertension in pregnancy $(\mathrm{P}=0.146)$. Few other studies also reported a non-significant association between occupation and hypertension.

There are many factors with which the women were more prone to develop hypertension. For examples if a patient had a history of pregnancy induced hypertension or had a history of chronic hypertension or a family relative with a history of hypertension [5]. This may be explained by the fact that hypertensive status is usually not known to the pregnant women, especially ones belonging to rural background and most of pregnant women of rural areas visit hospital only after 20 weeks when definitive symptoms appear. This reason might lead to misclassification of hypertension in pregnancy as PIH in hospital-based study Scholl et al. 1990). Hypertension in pregnancy prevalence was significantly higher in women with previous history of cesarean section (17.6 vs $6.5 \%$ ) than women with no history of cesarean section. The prevalence of hypertension in pregnancy was significantly higher in women with history of preterm delivery ( 24.1 vs $6.3 \%$ ) compared to those without history of preterm delivery.

\section{Conclusion}

From the result of this study, it can be concluded that among the respondent $44 \%$ presented with malnutrition and the associated risk factors included socio-economic factors, behavioral factors, clinical factors and reproductive factors. There is evidence that suggests individual with these factors remain at a high risk for developing malnutrition $[22,23]$. From the present study it was evident that the women with higher educational status were more conscious during their pregnancy period, complications and also very much positive in taking care of those factors that could minimize the threat to their baby as well as to them. On the contrary it is also seen that women with poor educational background possessed a lower economic status. Even they could not give birth to their baby in a hygienic environment [25]. Pregnancy related complications are still major problems in Bangladesh even though Bangladesh is well on its way towards achieving the Millennium Development Goal 5 (Improving maternal Health). Due to lack of proper facilities, awareness and education on these complications are extremely important to improving maternal health further [2628].

\section{Conflict of Interest}

The authors declare no conflict of interest.

\section{References}

1. Nokes C, Van den Bosch C, Bundy DAP (1998) The effects of iron deficiency and anemia on mental and motor performance, educational achievement, and behavior in children: a report to the International Anemia Consultative Group. Washington, DC: ILSI Press.

2. (1993) World Bank. Investing in health: world development indicators. Washington, DC: World Bank.

3. De Onis M, Villar J, Gulmezoglu M (1998) Nutritional interventions to prevent intra-uterine growth retardation: evidence from randomized control trials. Eur J Clin Nutr 52(suppl): S83-93.

4. Merchant KM, Kurz KM (1993) Women's nutrition through the life cycle: social and biological vulnerabilities. In: Koblinsky M, Timyan J, Gay J (Eds.), The health of women: a global perspective. Boulder, CO: Preview Press.

5. Tinker A, Koblinsky MA (1994) Making motherhood safe. Washington, DC: World Bank. (World Bank discussion paper 202).

6. Chatterjee M, Lambert J (1989) Women and nutrition reflections from India and Pakistan. Food Nutr Bull 11: 13-18.

7. (1997) World Health Organization. Coverage of maternity care: a listing of available information. Geneva: World Health Organization. (WHO/ RHT/MSM/96.28.)

8. McGuire J, Popkin BM (1998) Beating the zero-sum game: women and nutrition in the third world. Part I. Food Nutr Bull 11: 38-63.

9. Merchant KM, Martorell R (1988) Frequent reproductive cycling: does it lead to nutritional depletion of mothers? Prog Food Nutr Sci 12: 339369.

10. Black AK, Allen LH, Pelto GH, De Mata MP, Chavez A (1994) Iron, vitamin B-12 and folate status in Mexico: associated factors in men and women and during pregnancy and lactation. J Nutr124: 1179-1188.

11. Jellife DB (1966) The assessment of the nutritional status of the community. Geneva: World Health Organization.

12. (1996) World Health Organization. United Nations Children's Fund. Revised 1990 estimates of maternal mortality: a new approach by WHO and UNICEF. Geneva: WHO, (WHO/FRH/MSM/96.11.)

13. Bruner AB, Joffe A, Duggan AK, Casella JF, Brandt J (1996) Randomized study of cognitive effects of iron supplementation in non-anemic irondeficient adolescent girls. Lancet 348: 992-996.

14. Scholl TO, Hediger ML (1994) Anemia and iron-deficiency anemia: compilation of data on pregnancy outcome. Am J Clin Nutr 59 (suppl): 492S-500S. 
15. Lechtig A, Shrimpton R (1997) Maternal nutrition: what relevance for childrens' survival and development? In: Kretchmer N, Quilligan EJ, Johnson JD, eds. Prenatal and perinatal biology and medicine. Chur, Switzerland: Harwood Academic Publishers: 93-160

16. Jellife DB, Maddocks I (1964) Ecological malnutrition in the New Guinea highlands. Clin Pediatr 3: 432-438.

17. (1998) Population Reference Bureau. Women of our world (1998) Washington, DC: Population Reference Bureau.

18. Royston E, Armstrong S (1989) Preventing maternal deaths. Geneva: World Health Organization.

19. Leon DA (1997) Fetal growth and adult disease. Eur J Clin Nutr 52(suppl): S72-82.

20. Grantham-McGregor SM (1992) The effect of malnutrition on mental development. In: Waterlow JC, Grantham-McGregor SM, Tomkins A, eds. Protein energy malnutrition in third world children. London: E Arnold of Hodder Stoughton Ltd, 344-360.

21. Loaiza E (1989) Maternal nutrition status. Demographic and health survey comparative report no. 24. Calverton, MD: Macro International, Inc, Lettenmeier C, Liskin L, Church C, Harris J. Mother's lives matter: maternal health in the community. Popul Rep Series L 7.

22. Leslie J (1991) Women's nutrition: the key to improving family health in developing countries. Health Policy Plan 6: 1-19.

\section{ISSN: 2574-1241}

DOI: 10.26717/BJSTR.2021.36.005881

Hamida Khanum. Biomed J Sci \& Tech Res

(c) (P) This work is licensed under Creative

Submission Link: https://biomedres.us/submit-manuscript.php
23. Scholl TO, Hediger ML, Ances IG (1990) Maternal growth during pregnancy and decreased infant birth weight. Am J ClinNutr 51: 790793.

24. James WPT, Ferro-Luzzi A, Waterlow JL (1988) Definition of chronic energy deficiency in adults. Report of a working party of the International Dietary Consultative Group. Eur J Clin Nutr 42: 969-981.

25. Martorell R, Ramakrishnan U, Schroeder DG, Melgar P, Nenfeld L (1998) Intrauterine growth retardation, body size, body composition and physical performance in adolescence. Eur J Clin Nutr 52(suppl): S43-53.

26. Bhatia D, Seshadri S (1993) Growth performance in anemia following iron supplementation. Indian Pediatr 30: 195-200.

27. Adair LS (1987) Nutrition in the reproductive years. In: Johnson FE, ed Nutritional anthropology Alan R Lis, New York.

28. Barker DJP (1994) Mothers, babies and disease in later life. London: BMJ Publishing Group.

29. Viteri FE (1994) The consequences of iron deficiency and anemia in pregnancy. In: Allen L, King J, Lonnerdal B, (Eds.), Nutrient regulation during pregnancy, lactation, and infant growth. New York: Plenum Press: 127-140.

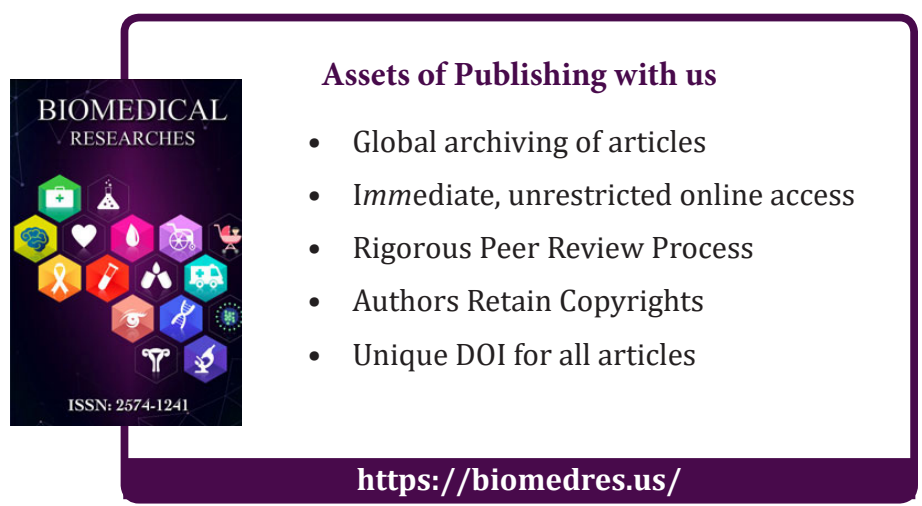

